\title{
INHALATION EXPOSURE TO DIOXINS AND DL-PCBS DEPENDING ON THE SEASON IN UPPER SILESIA, POLAND: A PILOT STUDY
}

\author{
Grzegorz Dziubanek', Ewa Marchwińska², Ilona Hajok², Agata Piekut ${ }^{2}$ \\ ${ }^{1}$ Department of Environmental Health Risk Factors, School of Public Health in Bytom, Medical University of Silesia in Katowice, Bytom, Poland \\ ${ }^{2}$ Department of Environmental Health, School of Public Health in Bytom, Medical University of Silesia in Katowice, Bytom, Poland
}

\section{SUMMARY}

Aim: The aim of this study was to investigate the seasonal fluctuation of PCDD/Fs and dl-PCBs levels in the ambient air of Upper Silesia in the aspect of human inhalation exposure as well as the estimation of health risk attributed to this exposure pathway to dioxins and dl-PCBs.

Methods: In the study air samples were taken in five urban districts of Upper Silesia, Poland, where the houses are heated with coal. The same sampling points in summer and winter were analyzed for dioxins/furans and dl-PCBs. In addition, information was collected on awareness of the residents about the co-incineration of plastic waste and effects of this activity on human health.

Results: The results show that the average daily exposure of residents of Upper Silesia to TCDD and DLCs in the heating season was about 6.5.-fold higher than in summer. The risk assessment showed that expected excess of cancer cases per 1,000,000 people ranged from 4.5 to 13.2 in winter and from 0.9 to 2.1 in summer. The practice of mixing waste with coal for houses heating has been confirmed by investigated families, who do not associate it with the possibility of negative health effects.

Conclusions: Air pollution can be a significant source of dioxin and dl-PCB for people during the winter season, as a result of co-burning coal and waste containing plastics. The dose of dioxins inhaled through the respiratory pathway in winter can be associated with the higher cancer risk in the population of Upper Silesia.

Key words: air pollution, dioxins, polychlorinated biphenyls, inhalation, exposure, health risk

Address for correspondence: G. Dziubanek, Department of Environmental Health Risk Factors, School of Public Health in Bytom, Medical University of Silesia in Katowice, Piekarska 18, 41-902 Bytom, Poland. E-mail: gdziubanek@sum.edu.pl

http://dx.doi.org/10.21101/cejph.a4286

\section{INTRODUCTION}

Dioxins and polychlorinated biphenyls (PCBs) are toxic chemicals that persist in the environment and due to their lipophilic properties accumulate in fatty tissues of organisms in the food chain. They can have adverse effects on nervous, immune and endocrine systems, impair reproductive function and may cause cancer (1-3). Dioxins and PCBs are widely distributed throughout the environment and typically occur as chemical mixtures. Because of a potentially high exposure of the population to them by food, dioxins and PCBs represent an important public health issue internationally. Investigations have indicated that dietary intake represents the main route of human exposure to dioxins and PCBs and that about $95 \%$ of the acceptable daily dose of Polychlorinated Dibenzodioxins (PCDD/F) and PCBs gets into our organisms with food $(4,5)$.

In order to describe the toxicity of mixtures of dioxins and PCBs, toxicity equivalency (TEQ) was developed and the magnitude of toxicity of separate compounds is compared to the most toxic congener of dioxins, 2,3,7,8-Tetrachlorodibenzo-p-dioxin $(2,3,7,8$-TCDD) which is assigned the value of 1 . In 2002, the Joint Food and Agriculture Organization of the United Nations (FAO) and the WHO Expert Committee on Food Additives
(JECFA) established a provisional tolerable intake of $70 \mathrm{pg} /$ $\mathrm{kg}$ body weight per month for PCDDs, PCDFs and coplanar PCBs expressed as Toxicity Equivalence Factor (TEF), based on reproductive end-points (6). The Agency for Toxic Substances and Disease Registry (ATSDR) assessed the non-cancer risks from dioxin exposure by setting minimal risk levels (MRLs) for acute, sub-chronic and chronic exposures to dioxins, and the chronic MRL was set at $1 \mathrm{pg}$ TEQ/kg/day (7). The Scientific Committee for Food of the European Commission set a tolerable

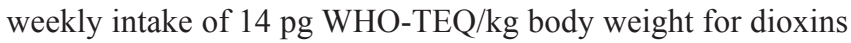
and dioxin-like PCBs (8). Most recently, the US Environmental Protection Agency (US EPA) has proposed a reference dose for long term exposure to dioxins and dl-PCBs of $4.9 \mathrm{pg} \mathrm{TEQ} / \mathrm{kg}$ body weight per week (9).

Dioxins and polychlorinated biphenyls (PCBs) are considered together as a group for setting guidelines (6). An air quality guideline for PCBs was not established, because, according to WHO the direct inhalation exposures constitute only a small proportion of the total exposure, i.e. $1-2 \%$ of the daily intake from food (10).

The aim of this study was to investigate the seasonal fluctuation of PCDD/Fs and dl-PCBs levels in the ambient air of Upper Silesia in the aspect of human inhalation exposure as well as the 
estimation of health risk attributed to this exposure pathway to dioxins and dl-PCBs.

\section{MATERIALS AND METHODS}

Ambient air samples were collected in five urban districts of Upper Silesia in: Dabrowa Gornicza - Losien (DGL), Dabrowa Gornicza - Zabkowice (DGZ), Cynkow (CK), Zbroslawice (ZC), and in Bytom (BY). Upper Silesia is located in southern Poland and it is the most industrialized region in the country. The sampling points in DGL and DGZ were located about 1,200 $\mathrm{m}$ and 4,500 $\mathrm{m}$ from hazardous waste incinerator. The sampling point was located in CK because its residents used to incinerate a coal mixed with waste material of polyvinyl chloride from the local production. The BY sampling point is in the centre of the city where household coal combustion and traffic air pollution exist. The last sampling point in $\mathrm{ZC}$ is the reference point (Fig. 1). The air samples were collected in summer and winter (heating season) by using high volume sampler (Staplex ${ }^{\circledR}$, model TFIA-2, USA). The sampler was operated at $0.9 \mathrm{~m}^{3} \mathrm{~min}^{-1}$ flow rate during 8 hours. Air volumes taken at each station were $432 \mathrm{~m}^{3}$. A quartz fiber filters (filter diameter $10.16 \mathrm{~cm}$; particle $0.3 \mu \mathrm{m}$, retention efficiency 99.98\%) were used to collect dust particles. In a pilot study one sample in summer and winter from each sampling point were collected. Meteorological parameters at sampling points are presented in Table 1.

The samples were analyzed by the certified laboratory of Chemistry Department of Krakow University of Technology. The analytical equipment used by this laboratory is CE Trace 2000 gas chromatograph coupled with an ion trap Finnigan GCQ Plus $\mathrm{GC}-\mathrm{MS} / \mathrm{MS}$ mass spectrometer. For the determination of PCDDs/ Fs, DB-5 MS column (J\&W Scientific; $60 \mathrm{~m} \times 0.25 \mathrm{~mm}$ and phase thickness of $0.25 \mu \mathrm{m}$ ) and DB-17 column (J\&W Scientific; $30 \mathrm{~m}$ $\times 0.25 \mathrm{~mm}$ and phase thickness of $0.25 \mu \mathrm{m}$ ) were used.

Toxic equivalent quantities (TEQ) were calculated by multiplying the concentration of individual PCDD/PCDFs and dl-PCBs congeners with corresponding TEFs proposed by the international system (11). The results were presented as $\mathrm{fg} / \mathrm{m}^{3}$ and their toxic equivalent as $\mathrm{fg} \mathrm{I}-\mathrm{TEQ} / \mathrm{m}^{3}$ together with the weekly intake of $\mathrm{PCDD} / \mathrm{F}$ and dl-PCBs through inhalation per kg of body weight for adults and children.

The inhalation exposure of residents of selected cities in Upper Silesia were calculated for health risk assessment, using the data of dioxins and dl-PCBs in air and daily inhalation values rates for adults $\left(20 \mathrm{~m}^{3} /\right.$ day) and children $\left(12 \mathrm{~m}^{3} /\right.$ day $)$, according to recommendation of US EPA(12). In order to calculate non-carcinogenic health risk the hazard quotient (HQ) was used. The hazard quotient less than 1 is assumed to be safe. When HQ exceeds 1, there may be concern for potential non-carcinogenic effects. In the equation

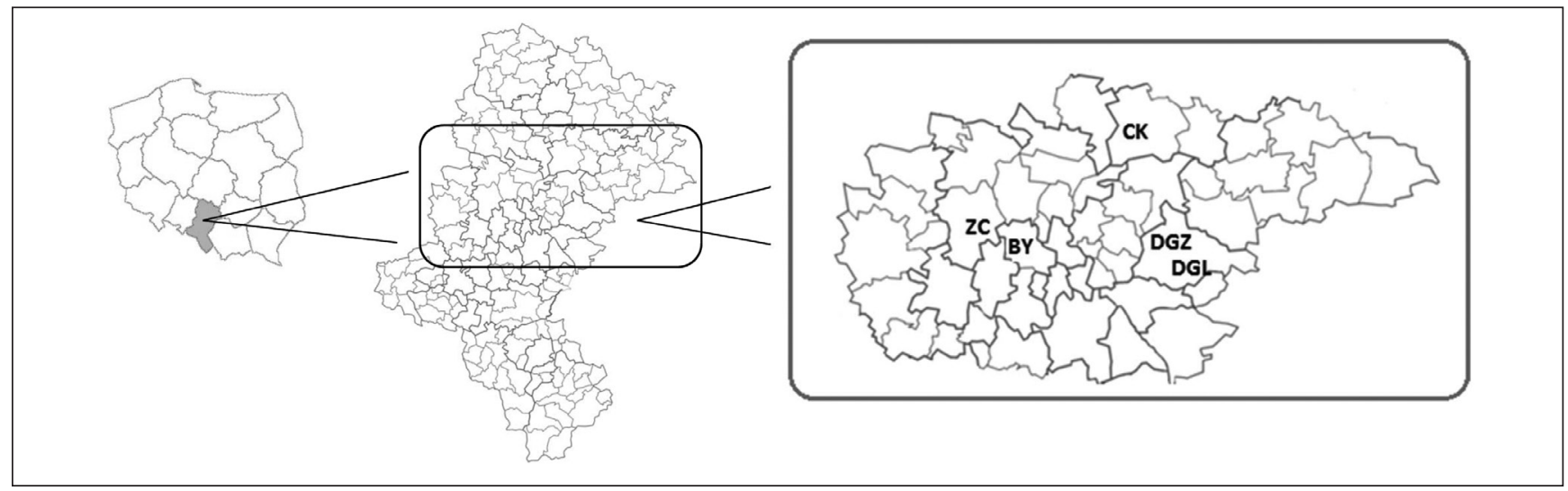

Fig. 1. Location of sampling points.

Table 1. Average values of meteorological parameters at sampling points

\begin{tabular}{|l|l|c|c|c|c|c|c|}
\hline \multicolumn{2}{|l|}{ Sampling station } & $\begin{array}{c}\text { Temperature } \\
\left({ }^{\circ} \mathrm{C}\right)\end{array}$ & $\begin{array}{c}\text { Humidity } \\
(\%)\end{array}$ & $\begin{array}{c}\text { Precipitation } \\
(\mathbf{m m})\end{array}$ & $\begin{array}{c}\text { Wind velocity } \\
(\mathbf{k m} / \mathrm{h})\end{array}$ & $\begin{array}{c}\text { Atmospheric } \\
\text { pressure }(\mathrm{hPa})\end{array}$ & Wind direction \\
\hline \multirow{2}{*}{ DGL } & heating season & -2 & 67 & 0 & 21 & $1,012.5$ & $\mathrm{E}$ \\
\cline { 2 - 9 } & summer & 22 & 69 & 0 & 8 & $1,014.7$ & SW \\
\hline \multirow{3}{*}{ DGZ } & heating season & -13 & 91 & 0 & 6 & $1,000.5$ & $\mathrm{NE}$ \\
\cline { 2 - 9 } & summer & 23 & 66 & 0 & 9 & $1,018.6$ & EN \\
\hline \multirow{3}{*}{ CK } & heating season & -11 & 93 & 0 & 8 & $1,019.0$ & SE \\
\cline { 2 - 9 } & summer & 20 & 73 & 0 & 12 & $1,015.1$ & SW \\
\hline \multirow{3}{*}{ ZC } & heating season & 0 & 100 & 0 & 5 & $1,002,9$ & SE \\
\cline { 2 - 9 } & summer & 21 & 75 & 0 & 14 & $1,010.9$ & SW \\
\hline \multirow{2}{*}{ BY } & heating season & 0 & 100 & 0 & 11 & $1,006.2$ & SE \\
\cline { 2 - 9 } & summer & 22 & 69 & 0 & 8 & $1,015.2$ & W \\
\hline
\end{tabular}


the reference dose (RfD) of $0.7 \mathrm{pg} \mathrm{kg}^{-1}$ b.w. day ${ }^{-1}$ were used. This RfD was established for TCDD but US EPA recommends the use of TEF values developed by the World Health Organization for the assessment of mixtures of TCDD and dioxin-like compounds (DLCs) (9). The inhalation cancer slope factor (CSF) of $1.5 \times 10^{5}$ $(\mathrm{mg} / \mathrm{kg} / \mathrm{d})^{-1}$ was used to calculate carcinogenic risk (14). CSF is an plausible upper-bound estimate of the increased risk of developing cancer from a lifetime exposure to TCDD and DLCs. The cancer risk estimates resulting from direct air inhalation were calculated by multiplying CSF by the daily respiratory exposure to dioxins and dl-PCBs. The cancer risks estimates less than $10^{-6}$ are assumed as acceptable risk, but when they range from $10^{-6}$ to $10^{-4}$ they are assumed to be of potential significance. Other calculation - the respiratory unit risk estimate (URE) of $3.3 \times 10^{-5}\left(\mathrm{pg} / \mathrm{m}^{3}\right)^{-1}$ for $2,3,7,8$-TCDD were used in order to evaluate the excess cancer cases (upper bound estimate) that are expected to be developed per $1,000,000$ people if exposed daily for a lifetime to $1 \mu \mathrm{g}$ of the substance in $1 \mathrm{~m}^{3}$ of air (13).

Additionally, the inhabitants $(\mathrm{n}=87)$ were interviewed personally about practices of mixing waste with coal for heating the houses and about their awareness as to the relationship between the combustion of wastes and increasing exposure to dioxins and possible health effects.

\section{RESULTS AND DISCUSSION}

The TEQ value of PCDDs/Fs and dl-PCBs in ambient air samples ranged from 26 to $400 \mathrm{fg} / \mathrm{m}^{3}$ and was higher in the cold season compared to the summer one. The PCDDs/Fs and dl-PCBs concentrations in winter were approximately 4 to 13 times higher compared to those in summer (Table 2).

The TCDD and DLCs content measured in sampling points of Upper Silesia are comparable to the dioxin content in other urban sites in European countries as Spain and Italy $(15,16)$, but was higher than those in Germany, where the National German target value of $150 \mathrm{fg} \mathrm{WHO}-\mathrm{TEQ} / \mathrm{m}^{3}$ (including coplanar PCBs) has been met at all sampling stations since 1999 (17).

These seasonal variations of dioxin levels are probably due to emission from the domestic heating in the cold season and from co-burning waste in household stoves, usually equipped with grate furnaces for coal burning. The practice to mix poor quality coal with high-energy plastic waste and to burn it in household stoves is still popular in many countries. Higher levels of PCDDs/Fs during colder seasons have been recognized by other researchers $(18,19)$.

The average daily exposure of residents of Upper Silesia to TCDD and DLCs in the heating season was about 6.5-fold higher than in the summer. The highest difference between seasons was detected in CK (13.7-fold) whereas the lowest in DGZ and ZC (3.8-fold). During the heating season the highest daily exposure was detected in CK and BY, in the summer season in BY. The average exposure of children was more than 1.5-higher than adults (Fig. 2). The highest air contamination in the winter and summer season in BY is associated with emissions from domestic heating, road traffic and industry, whereas high content of TCDD and DLCs during the heating season in air of rural site $(\mathrm{CK})$ is the result of emissions from domestic heating based on coal combustion and polyvinyl chloride wastes from local production. The lowest difference between the summer and winter of TCDD and DLCs levels in ambient air in DGL is attributed to the small distance of sampling station from the waste incinerator plant and strong wind during sampling in the winter season.

The risk assessment (Table 3) for non-carcinogenic health effects demonstrated that the daily inhalation exposure of inhabitants of Upper Silesia to dioxin and dl-PCBs are lower than tolerable daily intake. The quotient obtained for adults ranged from 0.056 to 0.163 in the heating season and from 0.011 to 0.026 in the summer. In population of children HQ ranged from 0.087 to 0.225 in the heating season and from 0.017 to 0.254 in the summer.

Inhalation exposure to TCDD and DLCs was associated with carcinogenic risk in the range of $1 \times 10^{-5}$ to $1 \times 10^{-6}$. The cancer risk in the most polluted cities in the winter cannot be ignored because of potential threat. This study presents proofs of importance of respiratory route in total exposure to dioxins and dl-PCBs, because in five urban districts of Upper Silesia the excess cancer cases (upper bound estimate) expected to develop per 1,000,000 people ranged from 4.5 to 13.2 in the winter season and from 0.9 to 2.1 in summer. The highest lifetime cancer risk estimates resulting from direct air inhalation in $\mathrm{BY}$ and $\mathrm{CK}$ were calculated.

Table 2. Content of PCDD/Fs and dl-PCBs in respirable dust in urban districts of Upper Silesia depending on the season (summer, heating season)

\begin{tabular}{|c|c|c|c|c|c|}
\hline Location & Season & $\begin{array}{c}\sum \mathrm{PCDD} / \mathrm{F} \\
\mathrm{fg} / \mathrm{m}^{3}\end{array}$ & $\begin{array}{c}\sum \mathrm{PCDD} / \mathrm{F} \\
\mathrm{fg} \mathrm{l}-\mathrm{TEQ} / \mathrm{m}^{3}\end{array}$ & $\begin{array}{c}\sum \mathrm{dl}-\mathrm{PCBs} \\
\mathrm{fg} / \mathrm{m}^{3}\end{array}$ & $\begin{array}{c}\sum \text { dl-PCBs } \\
\text { fg WHO-TEQ } / \mathrm{m}^{3}\end{array}$ \\
\hline \multirow{2}{*}{ DGL } & heating season & $2,948.72$ & $254.56^{*}$ & $7,889.88$ & 21.16 \\
\hline & summer & 449.40 & $38.31^{*}$ & $1,247.32$ & $2.96^{*}$ \\
\hline \multirow{2}{*}{ DGZ } & heating season & $1,344.54$ & $125.98^{*}$ & $3,597.58$ & 10.47 \\
\hline & summer & 355.99 & $32.72^{*}$ & $1,373.96$ & $2.74^{*}$ \\
\hline \multirow{2}{*}{ CK } & heating season & $3,526.56$ & $323.09^{*}$ & $15,460.42$ & $31.81^{*}$ \\
\hline & summer & 211.90 & $19.83^{*}$ & 590.77 & $6.17^{*}$ \\
\hline \multirow{2}{*}{ ZC } & heating season & $1,382.90$ & $134.72^{*}$ & $3,700.23$ & 11.20 \\
\hline & summer & 811.90 & $36.74^{*}$ & 437.20 & $1.48^{*}$ \\
\hline \multirow{2}{*}{ BY } & heating season & $4,407.94$ & $375.89^{*}$ & $4,264.28$ & $24.66^{*}$ \\
\hline & summer & $1,217.92$ & $59.21^{*}$ & $1,671.20$ & $4.31^{*}$ \\
\hline
\end{tabular}

*on the basis of data taken from Dziubanek G., 2013 (14) 

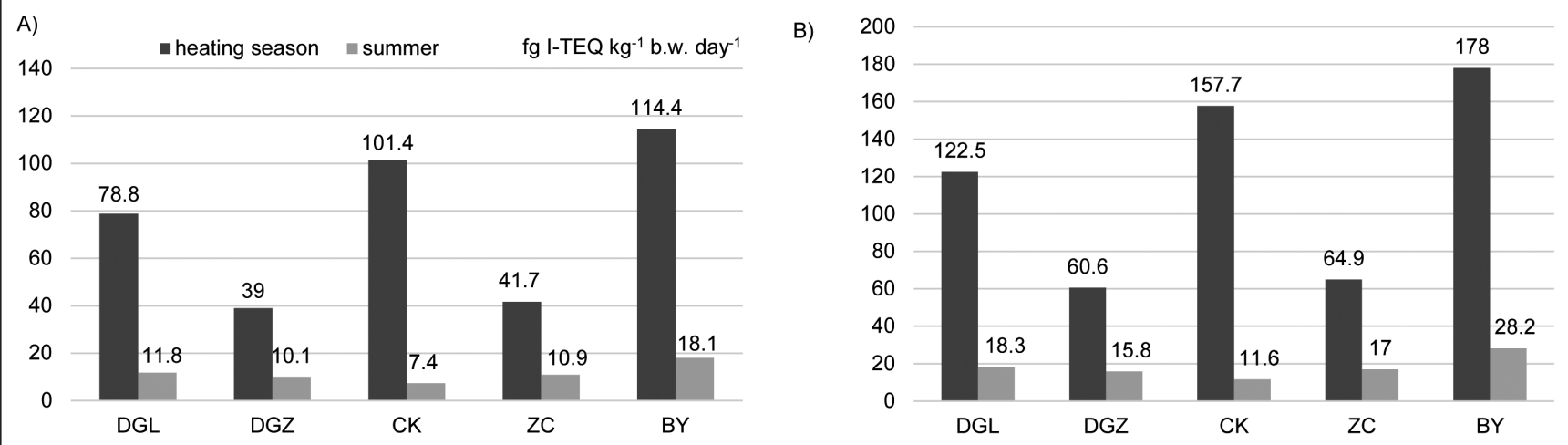

Fig. 2. Average daily respiratory exposure to PCDD/Fs and dl-PCBs of adults (A)* and children (B) (fg l-TEQ $\mathrm{kg}^{-1}$ b.w. day $\left.{ }^{-1}\right)$. *on the basis of the data taken from Dziubanek G., 2013 (14)

Table 3. Hazard quotient (HQ) and cancer risk resulting from respiratory exposure to PCDD/F and dl-PCBs.

\begin{tabular}{|l|l|c|c|c|c|c|}
\hline \multirow{2}{*}{ Location } & \multirow{2}{*}{ Season } & \multicolumn{2}{|c|}{ Hazard quotient } & \multicolumn{2}{|c|}{ Cancer risk } & $\begin{array}{c}\text { Excess cancer } \\
\text { cases per } 1,000,000 \\
\text { people }\end{array}$ \\
\cline { 3 - 7 } & & Adults & Children & Adults & Children & 9.1 \\
\hline \multirow{2}{*}{ DGL } & heating season & 0.113 & 0.175 & $1.18 \times 10^{-5}$ & $1.84 \times 10^{-5}$ & 1.4 \\
\cline { 2 - 7 } & summer & 0.017 & 0.026 & $1.77 \times 10^{-6}$ & $2.75 \times 10^{-6}$ & 4.5 \\
\hline \multirow{2}{*}{ DGZ } & heating season & 0.056 & 0.087 & $5.85 \times 10^{-6}$ & $9.10 \times 10^{-6}$ & 1.2 \\
\cline { 2 - 8 } & summer & 0.014 & 0.023 & $1.52 \times 10^{-6}$ & $2.36 \times 10^{-6}$ & 11.7 \\
\hline \multirow{2}{*}{ CK } & heating season & 0.145 & 0.225 & $1.52 \times 10^{-5}$ & $2.36 \times 10^{-5}$ & 0.9 \\
\cline { 2 - 8 } & summer & 0.011 & 0.017 & $1.11 \times 10^{-6}$ & $1.73 \times 10^{-6}$ & 4.8 \\
\hline \multirow{2}{*}{ ZC } & heating season & 0.060 & 0.093 & $6.25 \times 10^{-6}$ & $9.73 \times 10^{-6}$ & 1.3 \\
\cline { 2 - 8 } & summer & 0.016 & 0.024 & $1.64 \times 10^{-6}$ & $2.55 \times 10^{-6}$ & 13.2 \\
\hline \multirow{2}{*}{ BY } & heating season & 0.163 & 0.254 & $1.72 \times 10^{-5}$ & $2.67 \times 10^{-5}$ & 2.1 \\
\cline { 2 - 8 } & summer & 0.026 & 0.040 & $2.72 \times 10^{-6}$ & $4.23 \times 10^{-6}$ & \\
\hline
\end{tabular}

Inhalation rate for adults: $20 \mathrm{~m}^{3} /$ day, for children: $12 \mathrm{~m}^{3} / \mathrm{day}$

Body weight of adults: $70 \mathrm{~kg}$, of children: $27 \mathrm{~kg}$

The inhalation exposures to dioxins and PCBs have been somewhat neglected by the research community and policy-makers because the most significant uptake route of dioxins and furans is via the diet $(4,5)$. Recent studies have shown that in many European populations the diet exposure to PCDD/Fs exceeds safe dose i.e. the tolerable daily or weekly intake established by international institutions. Particularly disturbing is that this applies to children more often than to adults (20).

In view of the research results we can conclude, that the contribution of inhalation exposure to dioxins and furans to the total exposure can be significant in the cold seasons for inhabitants of many countries. Identification of the sources of health risks is vital to design and target prevention efforts. All of the inhabitants $(100 \%)$ who have been interviewed about practices of mixing waste with coal for heating their houses responded in the affirmative. Regardless of education, they did not associate these practices with possibility of negative health effects. A significant part of the respondents $(55 \%)$ were aware of the toxicity of dioxins but they associate the negative health effects resulting from the exposure to dioxins only to the contaminated food. Improvement of the situation can be accomplished by increasing the awareness of people about the relationship between the combustion of wastes and subsequent increasing exposure to dioxins as well as possible health effects.

This pilot study indicates the problem of health threat of Upper Silesia inhabitants associated with inhalation exposure to TCDD and DLCs. This study will continue with the same sampling points, with higher number of samples, using passive and active sampling measurements at each location for method verification.

In presented research, the estimated dose of dioxins inhaled through the respiratory pathway in the winter may be underestimated because the study was conducted at the beginning of the heating season, when the outside air temperature was higher than in the middle of the season, and therefore the amount of coal and waste used to heat homes was lower and consequently resulted in lower air contamination.

\section{CONCLUSION}

The air pollution can be a significant source of dioxin and dl-PCB for people during the heating season, as a result of co- 
burning coal and waste containing plastic. The dose of dioxins inhaled through the respiratory pathway in the winter can be associated with the excess cancer cases risk in the population of Upper Silesia.

\section{Acknowledgement}

The research was supported by Medical University of Silesia by the grant No. KNW-1-004/N/1/0, KNW-1-054/P/2/0 and KNW-1-072/N/4/0.

\section{Conflict of Interests}

None declared

\section{REFERENCES}

1. Arisawa K, Takeda H, Mikasa H. Background exposure to PCDDs PCDFs/PCBs and its potential health effects: a review of epidemiologic studies. J Med Invest. 2005 Feb;52(1-2):10-21.

2. National Toxicology Program. NTP toxicology and carcinogenesis studies of 3,3',4,4',5-pentachlorobiphenyl (PCB 126) (CAS No. 57465-28-8) in female Harlan Sprague-Dawley rats (Gavage Studies). Natl Toxicol Program Tech Rep Ser. 2006 Jan;(520):4-246.

3. Forns J, Lertxundi N, Aranbarri A, Murcia M, Gascon M, Martinez D, et al. Prenatal exposure to organochlorine compounds and neuropsychological development up to two years of life. Environ Int. 2012 Sep 15;45:72-7.

4. Parzefall W. Risk assessment of dioxin contamination in human food. Food Chem Toxicol. 2002 Aug;40(8):1185-9.

5. European Food Safety Authority (EFSA). Results of the monitoring of dioxin levels in food and feed. EFSA J. 2010; 8(3):1385-1419.

6. Evaluation of certain food additives and contaminants. World Health Organ Tech Rep Ser. 2002;909:i-x, 1-171.

7. Agency for Toxic Substances and Disease Registry (ATSDR). Public health assessment guidance manual. Atlanta (GA): ATSDR; 2005.

8. Commission Regulation (EC) No 199/2006 of 3 February 2006 amending Regulation (EC) No 466/2001 setting maximum levels for certain contaminants in foodstuffs as regards dioxins and dioxin-like PCBs. Off J Eur Union. 2006 Feb 4;49(L 32):34-8.

9. U.S. Environmental Protection Agency. EPA's reanalysis of key issues related to dioxin toxicity and response to NAS comments, volume 1. EPA/600/R-10/038F. Washington: U.S. EPA; 2012.
10. Prüss-Üstün A, Corvalán C. Preventing disease through healthy environments: towards an estimate of the environmental burden of disease. Geneva: WHO; 2006.

11. North Atlantic Treaty Organization, Committee on the Challenges of Modern Society. International toxicity equivalency factor (I-TEF) method of risk assessment for complex mixtures of dioxins and related compounds. Report no. 176. Brussels: NATO; 1988.

12. U.S. Environmental Protection Agency, National Center for Environmental Assessment, Office of Research and Development. Exposure factors handbook: 2011 edition. Washington: U.S. EPA; 2011.

13. U.S. Environmental Protection Agency. TTN Web - Technology Transfer Network. Air Toxics Web Site. 2,3,7,8-Tetrachlorodibenzo-p-Dioxin (2,3,7,8,-TCDD) [Internet]. Washington: U.S. EPA; 2013 [cited 2015 Jun 21]. Available from: http://www.epa.gov/ttnatw01/hlthef/dioxin.html.

14. Dziubanek G. Chemical risk factors in the human environment one of the most significant reasons of health inequalities of the society [dissertation]. Katowice: Medical University of Silesia in Katowice; 2013. (In Polish.)

15. Abad E, Martínez K, Gustems L, Gómez R, Guinart X, Hernández I, et al. Ten years measuring PCDDs/PCDFs in ambient air in Catalonia (Spain). Chemosphere. 2007 Apr;67(9):1709-14.

16. Menichini E, Iacovella N, Monfredini F, Turrio-Baldassarri L. Atmospheric pollution by PAHs, PCDD/Fs and PCBs simultaneously collected at a regional background site in central Italy and at an urban site in Rome. Chemosphere. 2007 Sep;69(3):422-34.

17. Bruckmann P, Hiester E, Klees M, Zetzsch C. Trends of PCDD/F and PCB concentrations and depositions in ambient air in Northwestern Germany. Chemosphere. 2013 Nov;93(8):1471-8

18. Grochowalski A, Konieczyński J. PCDDs/PCDFs, dl-PCBs and HCB in the flue gas from coal fired CFB boilers. Chemosphere. 2008 Aug;73(1):97-103.

19. Shin SK, Jin GZ, Kim WI, Kim BH, Hwang SM, Hong JP, et al. Nationwide monitoring of atmospheric $\mathrm{PCDD} / \mathrm{Fs}$ and dioxin-like $\mathrm{PCBs}$ in South Korea. Chemosphere. 2011 May;83(10):1339-44.

20. Bergkvist C, Oberg M, Appelgren M, Becker W, Aune M, Ankarberg $\mathrm{EH}$, et al. Exposure to dioxin-like pollutants via different food commodities in Swedish children and young adults. Food Chem Toxicol. 2008 Nov;46(11):3360-7. 